\title{
Crystal structure of Auer rods in acute myeloblastic leukaemia (AMyL)
}

\author{
EC PEARSON
}

From the Department of Haematological Medicine, University Clinical School, Cambridge

SUMMARY Ultrathin sections containing Auer rods from cases of acute myeloblastic leukaemia $(A M y L)$ were tilted in the goniometer stage of the electron microscope and the resulting series of electronmicrographs analysed in an optical diffractometer illuminated by laser. The results showed that Auer rods of AMyL show a truly three dimensional crystal structure. Measurements from the optical diffraction patterns were consistent with a monoclinic unit cell, the unit cell edge lengths a, $\mathrm{b}$, and c being $6.6((\mathrm{SD}) 0.5) \mathrm{nm}, 8.6(0.2) \mathrm{nm}$, and $9.6(1.0) \mathrm{nm}$, respectively; the angle between a and c being $120(7)^{\circ}$. This structure was quite distinct from the "tubular" substructure reported by others in the Auer rods of acute promyelocytic leukaemia (APL), although it was consistent with periodicities measured by others in Auer rods of AMyL. A complete understanding of the three dimensional structures of Auer rods in the different types of acute myeloid leukaemia (AML) could well prove to be of considerable diagnostic importance.

Auer rods, first observed at the beginning of the century by light microscopy, ${ }^{1}$ are cytoplasmic inclusions found only in the leucocytes of acute myeloid leukaemia (AML). It has been recognised for some time that at the ultrastructural level Auer rods often display internal periodicities ${ }^{2-4}$ and that their ultrastructure is different in acute promyelocytic leukaemia (APL) than in other subtypes of AML. ${ }^{56}$ It has never been formally shown, however, that Auer rods have true three dimensional crystal structures, and no attempt has been made to solve such structures. This paper presents the results of an initial study to investigate the three dimensional structure of Auer rods in acute myeloblastic leukaemia (AMyL), and a model for the structure is proposed. Studies of this type are important, not only to define accurately the ultrastructural differences that are already known to exist between the Auer rods of APL and the other subtypes of AML, but also to show any further ultrastructural differences, which may exist between Auer rods of the AML subtypes. Such differences would be of considerable diagnostic importance.

\section{Material and methods}

Clinical material used in this study was obtained from patients entered into the Medical Research Council 9th Acute Myeloid Leukaemia Trial. Aspirated bone

Accepted for publication 8 January 1986 marrow from cases of $\mathrm{AMyL}$ was conventionally fixed and embedded in Spurr's resin. ${ }^{7}$ Briefly, leucocytes and marrow fragments were separated from erythrocytes by centrifugation after layering the aspirate on a solution of Ficoll-Hypaque as described by Swirsky et al. ${ }^{8}$ The leucocytes and marrow fragments remaining at the interface were washed twice in $0.1 \mathrm{M}$ sodium cacodylate (pH 7.2) then fixed for one hour at room temperature in $1 \%$ glutaraldehyde, $0 \cdot 1 \mathrm{M}$ sodium cacodylate ( $\mathrm{pH} 7 \cdot 2)$. The fixed cells were washed twice as above, post fixed in $1 \%$ osmium tetroxide, $0 \cdot 1 \mathrm{M}$ sodium cacodylate $(\mathrm{pH} 7 \cdot 2)$ for 15 minutes at room temperature, and washed a further twice. Dehydration was through a graded ethanol series followed by propylene oxide (1,2-epoxypropane) and embedding in Spurr's resin ${ }^{7}$ to which had been added $1 \%$ silicone 200 fluid. $^{9}$ Ultrathin sections were stained in uranyl acetate and Reynolds' lead citrate. ${ }^{10}$ Electronmicrographs were recorded in a Zeiss EM 109 electron microscope fitted with a goniometer stage capable of tilting the specimen through $( \pm) 45^{\circ}$. Periodic structures in the micrographs were subsequently analysed in an optical diffractometer illuminated by laser. ${ }^{11}$ Optical diffraction patterns were recorded on Ilford Pan F $35 \mathrm{~mm}$ film, and the distances and relative angles of the diffracted spots from the origin were measured using a scale lupe to an accuracy of $(0.05) \mathrm{mm}$ (typically $<(2.5) \%)$ and $(0.5)^{\circ}$. The distances were related to the periodicities in the micrographs by comparison 

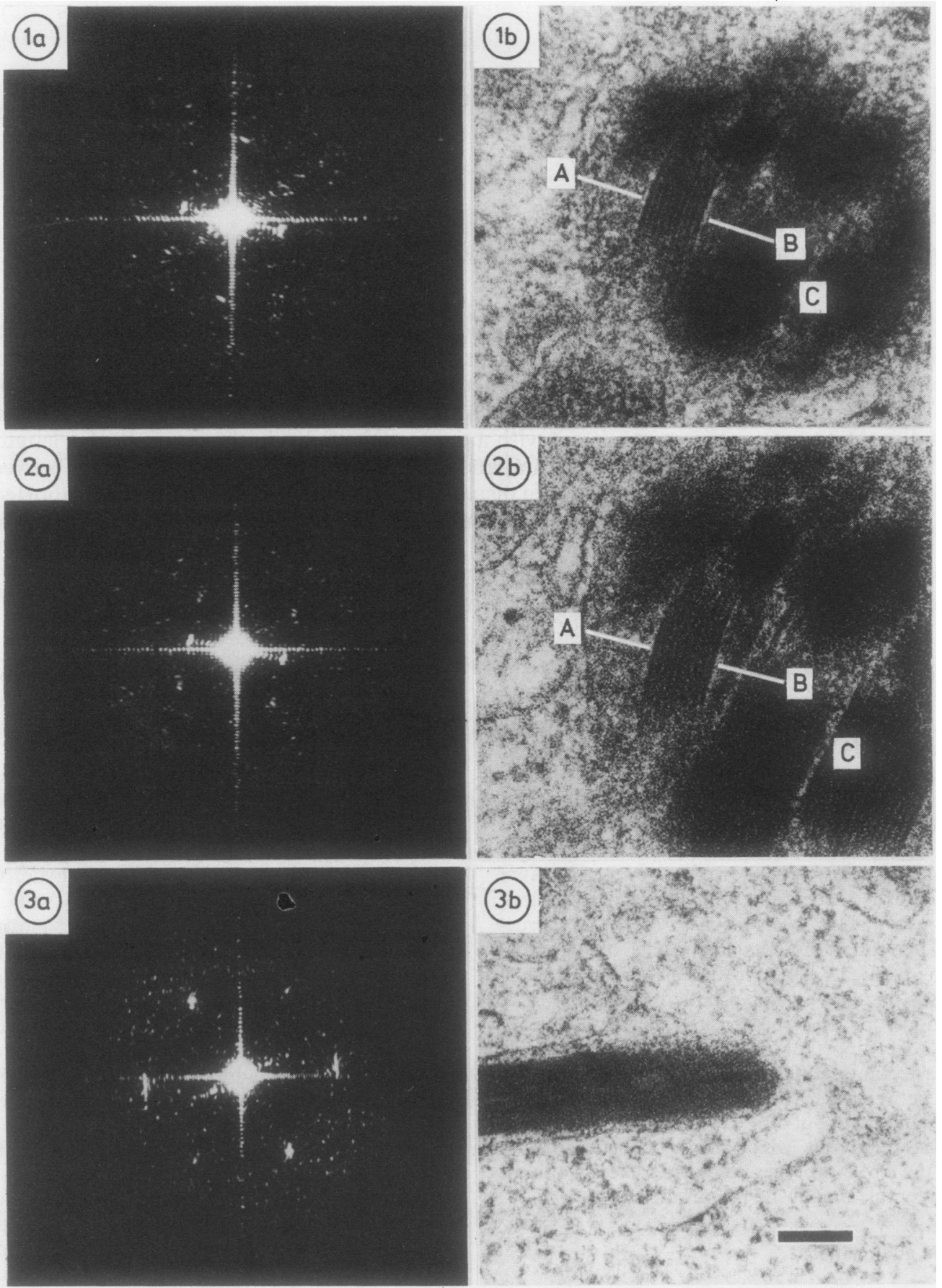

Figs. 1-3 Optical diffraction patterns (a) from electronmicrographs (b) of Auer rods found in $A M y L$.

Figs. 1 and 2 show same Auer rod and differ only by tilt angle of $55^{\circ}$ about axis $A B$. Planes perpendicular to axis $A B$ remained in register with periodicity of $\simeq 8.6 \mathrm{~nm}$ throughout tilting procedure. Planes giving rise to periodicity visible at $C$ in Fig. $2 b$ were not perpendicular to tilt axis $A B$, and consequently in Fig. $1 b$ this region appears amorphous. Fig. 3 shows hexagonal pattern in Auer rod from a second patient. Scale bar for electronmicrographs $=100 \mathrm{~nm}$. 


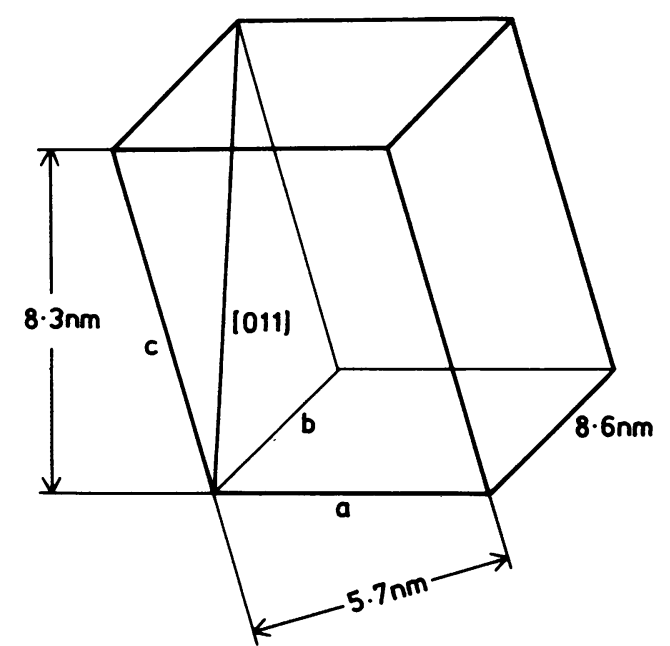

Fig. 4 Proposed monoclinic unit cell of Auer rods found in $A M y L$. For a crystal to be monoclinic the following must apply, $a, b$, and $c$ being unit cell edge lengths: $a \neq b \neq c$; angle between $a$ and $b=$ angle between $b$ and $c=90^{\circ}$; angle between $a$ and $c \neq 90^{\circ}$ and by convention $>90^{\circ}$. In present case $b(=8.6(0.2) \mathrm{nm})$ was obtained directly from diffraction patterns; angle between $a$ and $c\left(=120^{\circ}(7)^{\circ}\right)$ was obtained from $60^{\circ}(7)^{\circ}$ angle of tilt between strong patterns shown in Figs. 1 and $2\left(120^{\circ}=180^{\circ}-60^{\circ}\right)$; $a(=6.6(0.5) \mathrm{nm})$ and $c(=9.6(1.0) \mathrm{nm})$ were calculated from angle of tilt and observed spacings of $5.7(0.4 \mathrm{~nm}$ and $8.3(0.9) \mathrm{nm}$. Zone axis [011] is indicated.

with diffraction spots obtained under identical conditions from a graticule of known periodicity. Spacings in the original structures were calculated from the spacings in the micrographs, values for the magnifications of the micrographs having first been calculated from the corresponding electron microscope objective lens currents, using calibration data supplied by the manufacturer.

\section{Results}

The strongest periodicity observed in Auer rods from AMyL was $8.6(0.2) \mathrm{nm}$, as determined by optical diffraction from 75 electronmicrographs. Tilting the Auer rods in the goniometer stage of the electron microscope, so that the strong $8.6 \mathrm{~nm}$ periodicity remained in register, showed two further sets of periodicities, both roughly perpendicular to the $8.6 \mathrm{~nm}$ repeat and separated by $60^{\circ}(7)^{\circ}$ of tilt. Figs. 1 and 2 show the optical diffraction patterns with the corresponding electronmicrographs. The patterns corresponded to spacings of $5.7(0.4) \mathrm{nm}(15$ determinations) and 8.3 (0.9) $\mathrm{nm}$ (seven determinations), respectively. Their existence showed that the structure was truly crystalline in three dimensions. Fig. 3 shows a hexagonal pattern with a $6 \mathrm{~nm}$ periodicity occasionally observed in randomly oriented Auer rods. The measurements, which correspond to spacings between parallel planes in the structure and the angles at which the planes intersect, may be used to calculate a model for the unit cell (smallest repeating unit) of the crystal. The results were consistent with a monoclinic unit cell (Fig. 4), the lengths of the unit cell edges (a, b, and c) being $6.6(0.5) \mathrm{nm}, 8.6(0.2) \mathrm{nm}$, and $9.6(1.0) \mathrm{nm}$, respectively, the angle between a and $\mathrm{c}$ being $120^{\circ}(7)^{\circ}$. The method of calculation leading to these conclusions is outlined in the legend to Fig. 4. For a more complete description of crystallographic nomenclature and conventions reference should be made to a standard text. ${ }^{12}$

Further work is required to refine and confirm the above findings. The strong hexagonal diffraction patterns, however, which have occasionally been obtained from micrographs of Auer rods in random orientations and which show a periodicity of about 6 $\mathrm{nm}$ (Fig. 3), are consistent with the view in the direction of the zone axis [011] of the proposed structure (Fig. 4).

\section{Discussion}

Showing that Auer rods in AMyL have a truly three dimensional crystal structure should resolve some of the conflicting reports that have arisen, in which the Auer rods of this disease have been described as amorphous, ${ }^{13}$ lamellar, ${ }^{14}$ or, in favourable sections, periodic in one or two dimensions, leading to an assumption of crystallinity in three dimensions. ${ }^{414}$ The present study does not, of course, prove that all Auer rods in AMyL are crystalline, but a crystalline Auer rod is consistent with an amorphous appearance if the section is observed in an orientation such that none of the crystal planes lie in register. In this study all the apparently amorphous Auer rods, which were observed in the goniometer stage of the electron microscope, showed periodicity in at least one direction when suitably tilted (Figs. $1 \mathrm{~b}$ and $2 \mathrm{~b}$ ).

The dimensions of the unit cell proposed here are consistent with the observations of Tulliez and Breton-Gorius, ${ }^{14}$ who described a two dimensional periodicity of $8.0 \mathrm{~nm} \times 6.0 \mathrm{~nm}$, and agree slightly less well with those of McDuffie, ${ }^{4}$ who reported a two dimensional array of $9.0-10.0 \mathrm{~nm} \times 6.0 \mathrm{~nm}$. Bessis and Breton-Gorius ${ }^{15}$ observed a single periodicity of $6.0-7.5 \mathrm{~nm}$. All these dimensions observed in cases of AMyL are different from those observed in the Auer rods of APL, the apparently tubular substructure of which has been widely reported elsewhere. ${ }^{3141617} \mathrm{~A}$ third type of Auer rod has been proposed on the basis of the ultrastructure visible after peroxidase cyto- 
chemistry in a case of acute myeloblastic leukaemia with giant granules, ${ }^{14}$ although here rather less is known about the structure.

It is clear that at least two, and probably three, different types of Auer rod have been found to be associated with different subtypes of AML. It seems likely, therefore, that a more complete understanding of the three dimensional structure of Auer rods would be of considerable diagnostic importance, as the subtypes of AML would then be readily distinguishable in the electron microscope. This would be possible by comparison of the periodicities visible in the Auer rods of any particular patient with the previously determined periodicities characteristic of the different types of leukaemia. Furthermore, a systematic study of the three dimensional structure of Auer rods might well show further, as yet undiscovered, differences between the subtypes of $A M L$, and this would again be of diagnostic importance.

I thank Dr JT Finch and Professor FGJ Hayhoe for invaluable discussion and critical comments on the manuscript. Thanks are also due to the clinicians participating in the Medical Research Council 9th Acute Myeloid Leukaemia Trial who provided clinical material, Miss W Gillson for excellent technical help and Mrs $\mathbf{J}$ Chandler for typing the manuscript. This work was financially supported by the Medical Research Council.

\section{References}

${ }^{1}$ Auer J. Some hitherto undescribed structures found in the large lymphocytes of a case of acute leukaemia. Am J Med Sci 1906;131:1002-15.

${ }^{2}$ Marchal G, Bessis M, Thiéry JP. Ultrastructure des corps d'Auer. Rev Hematol 1959;14:413-7.

${ }^{3}$ Kondo K, Yoshitake J, Takemura K. The fine structure of Auer bodies. J Electron Microsc (Tokyo) 1966;15:237-48.
${ }^{4}$ McDuffiie NG. Crystalline patterns in Auer bodies and specific granules of human leukocytes. J Microsc 1967;6:321-30.

${ }^{5}$ Breton-Gorius J, Gourdin MF, Reyes F. Ultrastructure of the leukemic cell. In: Catovsky D, ed. Methods in hematology. The leukemic cell. vol. 2. Edinburgh: Churchill Livingstone, 1981:87-128.

${ }^{6}$ Pearson EC, Matthews JG, Hayhoe FGJ. Ultrastructure and cytogenetics in seven cases of acute promyelocytic leukaemia (APL) $\mathrm{Br} J$ Haematol (in press).

${ }^{7}$ Spurr AR. A low viscosity epoxy resin embedding medium for electron microscopy. J Ultrastruct Res 1969;26:31-43.

${ }^{8}$ Swirsky DM, Watt SM, Gilmore DJ, Hayhoe FGJ, Waldmann H. The characterisation of monoclonal antibodies against haemopoietic cells: comparison of an immunoperoxidase method with fluorescence activated cell sorting. J Immunol Methods 1983;61:171-82.

${ }^{9}$ Langenberg WG. Silicone additive facilitates epoxy plastic sectioning. Stain Technol 1982;57:79-82.

${ }^{10}$ Reynolds ES. The use of lead citrate at high $\mathrm{pH}$ as an electronopaque stain in electron microscopy. J Cell Biol 1963; 17:208-12.

${ }^{11}$ De Rosier DJ, Klug A. Structure of the tubular variants of the head of bacteriophage T4 (polyheads). I. Arrangement of subunits in some classes of polyheads. J Mol Biol 1972;65:469-88.

${ }^{12}$ Stout GH, Jensen LH. X-ray structure determination. A practical guide. London: Collier-Macmillan, 1968.

${ }^{13}$ Senelar R, Janbon C, Taib J, et al. Acute myeloid leukemia with giant inclusions: cytochemical and ultrastructural study. Acta Haematol (Basel) 1984;71:165-73.

${ }^{14}$ Tulliez M, Breton-Gorius J. Three types of Auer bodies in acute leukemia. Visualization of their protein by negative contrast after peroxidase cytochemistry. Lab Invest 1979;41:419-26.

${ }^{15}$ Bessis M, Breton-Gorius J. Pathologie et asynchronisme de développement des organelles cellulaires au cours des leucémies aiguës granulocytaires. Etude au microscope electronique. Nouv Rev Fr Hematol 1969;9:245-78.

${ }^{16}$ Breton-Gorius J, Houssay D. Auer bodies in acute promyelocytic leukemia. Demonstration of their fine structure and peroxidase localization. Lab Invest 1973;28:135-41.

${ }^{17}$ Dixon BR, Mukherjee TM, Ho JQK. The ultrastructural identification of Auer body precursors in a case of acute promyelocytic leukemia using high-angle specimen tilt. Am J Clin Pathol 1984;81:132-7.

Requests for reprints to: Dr EC Pearson, Department of Haematological Medicine, University Clinical School, Hills Road, Cambridge CB2 2QL, England. 